\title{
NOVAS FORMAS DE SER: MÍDIA E TRANSEXUALIDADE A PARTIR DE NARRATIVAS DE (RE) CONSTRUÇÃO IDENTITÁRIA
}

\section{NEW WAYS OF BEING: MEDIA AND TRANSSEXUALITY FROM NARRATIVES OF IDENTITY (RE) CONSTRUCTION \\ NUEVAS FORMAS DE SER: LA TRANSEXUALIDAD EN NARRATIVAS DE (RE) CONSTRUCCIÓN IDENTITARIA}

Robéria Nádia Araújo Nascimento

Resumo: o texto apresenta uma reflexão sobre a transexualidade: a identificação dos indivíduos com o gênero oposto ao seu nascimento. Trata-se de uma análise contextual, derivada de uma pesquisa em curso2 à luz dos aportes teóricos alteridade (BHABHA, 2005), identidade (HALL, 2004) e estigmas (GOFFMAN, 1988), atrelada a um movimento empírico que notabiliza as vozes de transexuais masculinos e femininos a partir de suas narrativas (MEDINA, 2003; ALVES, 2008). As interlocuções apontam os tratamentos midiáticos concedidos ao fenômeno sugerindo sensibilidades e subjetividades à revelia de preconceitos que relegam as minorias sexuais ao silenciamento e à invisibilidade social.

Palavras-chave: Transexualidade. Representações sociomidiáticas. Identidades de gênero.

\begin{abstract}
: the text presents a reflection on the transsexuality: the identification of individuals with the opposite gender at birth. This is a contextual analysis, derived from a research in progress in the light of the theoretical alterity (Bhabha, 2005), identity

Universidade Estadual da Paraíba, Campina Grande, PB, Brasil.. Doutora em Educação pela Universidade Federal da Paraíba (UFPB). Professora do Programa de Pós-Graduação em Formação de Professores da Universidade Estadual da Paraíba, Campina Grande, PB, Brasil. ORCID: https://orcid.org/0ooo-0002-18060138. E-mail: rnadia@terra.com.br

2 O estudo em curso, além de verificar o tratamento midiático concedido à diversidade de gêneros, investiga as representações da sexualidade/transexualidade no âmbito das Igrejas Inclusivas no estado da Paraíba.
\end{abstract}


(Hall, 2004) and stigmas (Goffman, 1988), linked to an empirical movement that excels the voices of transgender men and women from their narratives (Medina, 2003; Alves, 2008). The Interlocutions indicate the media treatment granted to the phenomenon suggesting sensibilities and subjectivities in absentia of prejudices which relegate the sexual minorities to silence and to social invisibility.

Keywords: Transsexuality. Social media representations. Gender identity.

Resumen: Las representaciones sociomidiáticas son pretextos para una reflexión sobre la transexualidad: la identificación de los individuos con el género opuesto a su nacimiento. Este es un análisis contextual, derivado de una investigación en curso a la luz de la alteridad teórica (Bhabha, 2005), identidad (Hall, 2004) y los estigmas (Goffman, 1988), vinculado a un movimiento empírico que destaca las voces de hombres y mujeres transgénero desde sus narrativas (Medina, 2003; Alves, 2008). Las interlocuciones sugieren sensibilidades y subjetividades en rebeldía de prejuicios que relegan a las minorías sexuales al silenciamiento ya la invisibilidad.

Palabras clave: Transexualidad. Representaciones sociomidiáticas. Identidades de género.

\section{Introdução}

"O outro nos põe em questão. Tanto o que nós somos, como todas essas imagens que construímos para classificá-lo, para nos proteger de sua presença incômoda, para enquadrá-lo!" (Jorge Larrosa)

As balizas dos Estudos Culturais fundamentam as proposições buscando ratificar a interdisciplinaridade da comunicação no cruzamento com questões de cunho socioantropológico. A proposta é instigar uma reflexão sobre as construções identitárias de sujeitos transexuais. Para tanto, inicialmente, mobilizamos as formulações de Hall (2004). Na concepção do autor, a identidade é produto das experiências culturalmente compartilhadas e das negociações de sentidos entre os sujeitos, assim como as diferenças são (re)criadas por intermédio dos sistemas de representação social.

Sob essa lógica, os sentimentos identitários derivam de uma construção performativa marcada pela impermanência e inacabamento que transformam os modos de percepção de si nas trocas simbólicas do tecido cultural. Nesse raciocínio, as diferenças identitárias, atreladas às transições da historicidade, não são simétricas nem fixas, tampouco possuem eixos de estabilidade. Por 
isso, como sinaliza a epígrafe, o outro, que é diferente de nós, tende a ser alvo de estranhamentos e classificações.

Se a identidade e a diferença resultam de dinâmicas simbólicas e discursivas cambiantes, Silva (2008) entende que tanto uma categoria quanto a outra possuem naturezas flexíveis em razão das relações sociais que as redimensionam. Nesse processo, a atribuição de sentidos aos sujeitos guarda estreita vinculação com distinções hierárquicas: incluir/excluir (estes pertencem; aqueles, "não"), demarcar fronteiras (nós e "eles"), adjetivar (bons e "maus"), normalizar (somos "normais", eles, "não"), como se fosse possível, nas palavras do autor, existir uma identidade social sem costuras.

No limiar dos pressupostos teóricos indicados, nosso interesse recai sobre as identidades de gênero com ênfase na transexualidade para focalizar experiências significativas e intersubjetivas. Assim, a presente abordagem se ancora em expressões de sociabilidade das minorias sexuais articulando dados de uma pesquisa em curso ${ }^{3}$ que nos aproximou do referido contexto. O recorte teórico-empírico forjado nos diálogos com os participantes do estudo também nos pareceu oportuno para pensar as relações midiáticas com a problemática, pois, de modo espontâneo, as narrativas trans compartilhadas por nossos interlocutores indicam pistas nessa direção fazendo avançar a compreensão da diversidade de gênero.

O que os sujeitos trans têm a dizer sobre suas vidas e seus desafios? Tornase oportuno dar voz ao grupo em uma reflexão sobre as implicações das suas reconstruções identitárias, o que justifica a transcrição das narrativas com relatos de transição sexual. As falas nos levaram a entender que as representações midiáticas em torno das sexualidades dissidentes parecem reproduzir as polarizações e os lugares hegemônicos sociais. Tal premissa sinaliza que os segmentos sexualmente discriminados são pouco compreendidos e afetados pelo silenciamento. Por isso, as leituras em torno da invisibilidade são submetidas ao crivo das pessoas que a vivenciam.

Apoiando-se nesses eixos, a racionalidade metodológica privilegiada contempla uma revisão de literatura sobre a transexualidade com o objetivo de clarificar

\footnotetext{
3 Estudo é desenvolvido pelo Grupo de Pesquisa Comunicação, Cultura e Desenvolvimento, do Departamento de Comunicação Social da UEPB, com o objetivo de analisar a teologia inclusiva para conhecer as motivações dos seus praticantes. Entre os frequentadores da congregação de João Pessoa, locus da investigação, contatamos indivíduos trans que residem em Campina Grande e fomos impactados pelos seus relatos, que são socializados neste texto. A temporalidade de captura das falas se deu aleatoriamente para o estudo mencionado, uma vez que os depoimentos sobre transexualidade não foram previstos, mas apontam outros percursos que fazem avançar a pesquisa. Os relatos acentuam aspectos importantes sobre o tema nas suas relações com as mídias, daí optamos por difundir parte deles, antes da conclusão do estudo, em razão da transversalidade das questões narradas.
} 
as narrativas dos pesquisados, apresentadas ao final do texto. Dessa forma, a incursão analítico-conceitual se expande com a noção de estigmas (GOFFMAN, 1988) para iluminar as falas de transexuais masculinos e femininos, na tentativa de delinear os contornos de suas "alteridades" a partir da discussão dessa categoria teórica (BHABHA, 2005).

Narrativas são mais que recursos metodológicos de escuta porque oportunizam a interação com o campo estudado a fim de romper os seus silenciamentos. Sugerem, de acordo com Medina (2003), relações inacabadas porque abertas às incertezas das nossas interpretações em meio ao trabalho de campo ${ }^{4}$. Na dinâmica relacional, nem a fala nem a escuta são definitivas, mas percursos que favorecem descobertas contínuas nos encontros com diferentes sujeitos que tecem e reescrevem suas histórias de vida, representando "uma busca de informações enraizadas nos valores humanos para criar a arte do diálogo" (MEDINA, 2003, p. 33).

Em um pensamento similar, Alves (2008) propõe que as narrativas "dizem muito" sobre as singularidades cotidianas dos sujeitos. Daí a necessidade de ouvi-los para traduzir seus pensamentos. A apreensão dos ditos e a observação dos seus esquemas interpretativos não significam somente ações de "transcrever a fala num lugar de fala", mas um empenho ético para apontar os interditos "na proposta de sentir o mundo do outro, e não apenas olhar para ele", em um mergulho que exige "curiosidade, atenção e cuidado para se permitir ser tocado pelas histórias, conversas, emoções, silêncios, gestos que, de alguma forma, dizem o não dito e expressam uma realidade" (ALVES, 2008, p. 18).

\section{As dimensões de gênero e as representações da transexualidade no espaço social}

A compreensão do universo trans requer uma análise das representações sociais que incidem na construção identitária de gênero. Vários autores se debruçam sobre a ação complexa de "representar o mundo social", entrelaçando o viés sociológico/antropológico de seus estudos com o campo da comunicação, como fazem, entre outros, Martín-Barbero (2009), Maffesoli (2005) e Bourdieu (2009). Seus esquemas interpretativos nos permitem pensar na possibilidade de uma agenda midiática planejada para a superação de discriminações sociais.

4 Outros trechos das narrativas foram anotados no Diário de Campo seguidos de observações que também oferecem outras formas de exploração do contexto. 
Uma incursão teórica a respeito é iniciada com Martín-Barbero (2009), que explica as representações sociais como "modos comprometidos" de ver, escutar ou ler uma dada historicidade. A transexualidade, por sua vez, quebra os protocolos históricos e atravessa as redes de significação vigentes trazendo a ambiguidade para as questões de teor sexual. A incerteza em torno da sexualidade faz Ceccarelli (2010) afirmar que o "sentido do sexo é errante, vivendo em busca de determinações provisórias: nada determina nada; qualquer ordem simbólica social, embora necessária, é pura indeterminação" (CECCARELLI, 2010, p. 272).

As redes de significação da sociedade insistem em nomear grupos e relações criando uma dinâmica de padronização que afeta os indivíduos trans. O desconhecimento de quem são, marginaliza suas diferenças produzindo valorações negativas e intolerâncias. Segundo Martín-Barbero o trânsito das simbologias culturais gera mediações de significados que, por sua vez, originam hierarquias estereotipadas e exclusão social. Dito de outro modo, as representações são recriadas alimentando as hegemonias culturais.

Maffesoli (2005), no entanto, realça a proatividade necessária aos grupos excluídos, lembrando que a valorização das minorias depende da ruptura dos antagonismos e estereótipos. Logo, falar dos marginalizados, como as minorias sexuais, significa recuperar suas falas e desconstruir estigmas. Um olhar sobre a diversidade sexual exige, então, pensar o micro e o outro para visibilizar as diferenças que os constituem. Para tanto, é sugerido que devemos reconhecer o fim das homogeneidades sociais e das idealizações normativas de sexo, identidades, cor, idioma, classes ou etnias para subverter uma história cultural de preconceitos.

$\mathrm{Na}$ ótica de Bourdieu (2009), a transexualidade situa a identidade de gênero ${ }^{5}$ como categoria de transposição das polaridades sociais normativas e dos significados biológicos de masculino e/ou feminino. Os gêneros, enquanto "habitus sexuados", são construções "naturalizadas" na sociedade. A naturalização permite que a diferença biológica entre os sexos, e especificamente a diferença "anatômica" entre os órgãos sexuais, desconsidere as particularidades dos sujeitos e a multiplicidade de seus matizes psicológicos. O cenário da diversidade é criado quando os indivíduos que não se enquadram às normas heterossexuais rompem a doxa e ampliam o espaço dos possíveis em matéria de sexualidade humana.

\footnotetext{
5 Não confundir com orientação sexual, já que essa categoria é flexível e se vincula ao desejo de relacionamento das pessoas: se a atração é pelo sexo oposto, o mesmo sexo ou ambos. É uma identidade "não definitiva", uma vez que os mecanismos psicológicos do desejo não são previamente definidos.
} 
Por outro lado, Ceccarelli (2010) salienta que os termos homo ou transfobia não se referem, exclusivamente, ao âmbito da sexualidade. Os prefixos homo ou trans desafiam uma sexualidade compulsória, naturalizada, na qual o sexo biológico e suas analogias sexuais a machos e fêmeas determinam comportamentos preconcebidos. Dessa forma, a heteronormatividade também naturaliza as aversões que negam os padrões socioculturais legitimados.

Entretanto, vale destacar que no repertório cultural e discursivo da sociedade, "a presença ou a ausência do órgão sexual masculino ou feminino não constitui garantia de que os sujeitos se coloquem do lado de homens ou das mulheres" (CECCARELLI, 2010, p. 274). A construção da identidade de gênero depende de um reconhecimento de si que se desloca das condições anatomobiológicas dos sujeitos ou das representações sociais. Portanto, a transexualidade aponta o desejo de (re)constituição do eu de acordo com as pulsões internas dos indivíduos. Tal conceito engloba sujeitos transgêneros, como também travestis, em sentido amplo, que não realizam mudança de sexo cirúrgica, mas que se sentem, do ponto de vista psicológico e identitário, pertencentes a um gênero ou a outro. Condição que retrata a fluidez da noção de identidade, segundo os termos de Hall (2004).

A perspectiva fluida da identidade sexual não é novidade. O sentimento de pertencer a outro sexo presente no transexual é tão antigo quanto a própria sexualidade humana. Relatos mitológicos, fontes literárias e antropológicas sempre registraram personagens que se viam como sujeitos do outro sexo. $O$ que é recente, na verdade, é a possibilidade de se mudar fisicamente graças às técnicas cirúrgicas avançadas e à hormonoterapia' (CECCARELLI, 2010).

$\mathrm{Na}$ hierarquização de modelos de sexualidade, as normas sociais reiteram a heterossexualidade como uma postura "desejável", o que suscita visões negativas sobre os sujeitos trans. Aqueles que desviam dos padrões homogêneos, como assinala Louro (2013), "serão constituídos como 'abjetos'- aqueles que escapam da norma" (LOURO, 2013, p. 46), e "estigmatizados" porque não se adequam aos padrões. Entretanto, a autora assinala que o "não lugar" da sexualidade se articula também a outros marcadores sociais da diferença - classe, gênero, geração, raça-cor-etnia, determinando as variações dos estigmas e os graus da exclusão. Consequentemente, um transexual branco e rico pode ser mais aceito no espaço social do que um indivíduo pobre e negro, requerendo outra reflexão, que, por sua vez, extrapola o raciocínio aqui desenvolvido.

\footnotetext{
6 A terapia hormonal ou endocrinoterapia baseia-se no princípio de administração ou subtração de hormônios
} para fins de masculinização ou feminilização. 
Bento (2008) defende que, a discussão da transexualidade solicita, também, atenção à teoria queer ${ }^{7}$, essencial para pensar as assimetrias nas relações supostamente estáveis entre sexo cromossomático, gênero e desejo sexual. Em prol do respeito às liberdades individuais, o "gênero" se desvinculou do "sexo biológico" mostrando os modos pelos quais o conceito depende da formação sociocultural, à medida que contrariou a visão patologizadora das identidades minoritárias e interpelou os estereótipos binários.

Estudos nessa vertente incorporam a observação de gays, lésbicas, transexuais, travestis, transgêneros, drag queens ${ }^{8}$, drag kings ${ }^{9}$, crossdressers $^{10}$ e transformistas ${ }^{11}$. Indivíduos designados pela literatura médica "como sujeitos transtornados, enfermos, psicóticos, desviados, perversos, mas que constituem suas identidades mediante os mesmos processos que os considerados 'normais'" (BENTO, 2008, p. 6).

\section{A mídia e o universo trans: questões de gênero e afins}

Antes de apresentarmos as narrativas dos interlocutores transgêneros, achamos oportuno rastrear exemplos da relação mídia e transexualidade, pois suas falas se referem às tematizações midiáticas sobre a problemática. Especialmente no campo da comunicação Lopes (2004) aponta ridicularizações e estereótipos produzidos em torno das sexualidades em um "papel reafirmador ou crítico dos clichês das representações de gênero e de orientação sexual" (LOPES, 2004, p. 3).

Se os meios de comunicação ativam as representações sociais, faz-se necessário, como indica o autor, a criação de uma política identitária de confronto e marcação das diferenças contra a repetição das imagens negativas em favor de imagens positivas. Isso significa articular a diversidade de gênero e orientação sexual com as questões de classe, nacionalidade, condição periférica ou metropolitana e etnias, para evitar simplificações identitárias. A identidade, nesse prisma, não seria uma classificação de pessoas ou posturas, mas "experiências"

\footnotetext{
7 Em português pode significar o que é ridículo, exótico ou excêntrico. A filósofa Judith Butler é pioneira nesses estudos ao propor o caráter discursivo da sexualidade e produzir novas concepções sobre sexo, sexualidade e gênero. Em suma, a teoria advoga que as normas que regulam o sexo dos sujeitos precisam de repetição e reiteração através de performances sociais e linguísticas.

8 Homens que se vestem como mulheres.

9 Mulheres que se vestem e incorporam personagens do sexo oposto.

10 Indivíduos que usam roupas e objetos diferentes dos comuns ao seu sexo anatômico, como joias, perucas, saltos, entre outros, porém sem conotação sexual.

1 Termo que inclui as Drag queen e os Drag king em alusão a pessoas que, por entretenimento ou por intuitos comerciais, se vestem como o sexo oposto sem significados de orientação sexual ou identidade de gênero.
} 
sempre mediadas pelos discursos sociais, solicitando, portanto, a diversidade de narrativas nas múltiplas plataformas de informação.

Os enfoques da mídia sobre sexualidades também é objeto das pesquisas de Leal e Carvalho (2009). Os autores consideram que, no Brasil, as pautas midiáticas sobre o tema são "enviesadas". Segundo eles, não existem coberturas aprofundadas sobre os indivíduos trans e nem sobre a transfobia capazes de romper o silenciamento e a invisibilidade do segmento. As ações afirmativas das minorias sexuais são notabilizadas pelas militâncias das comunidades de Lésbicas, Gays, Bissexuais, Transexuais, Transgêneros e Intersexs (LGBTTIs), mas a mídia as reverbera de modo lacônico ou superficial.

Saleiro (2013) pensa que uma das razões para isso é a sistemática confusão resultante do senso comum sobre as definições de transgênero e homossexualidade, já que configuram realidades diferentes: enquanto a homossexualidade se refere à orientação sexual, relacionando-se com a sexualidade, no sentido de atração sexual; as identidades de gênero trans, conforme exposto, sinalizam a percepção de si.

A proximidade da imprensa com a diversidade sexual tem sido verificada na divulgação dos casos de homofobia e das "Paradas Gays". Contudo, na ótica de Leal e Carvalho (2009), tal postura perpetua a reprodução de estereótipos heteronormativos, uma vez que as coberturas sofrem desvios das editorias que seguem a égide da heteronormatividade. No caso da TV, existem algumas reportagens nos programas Profissão Repórter e Globo Repórter. Todavia, nas ocasiões em que tratam de episódios de violência contra tais indivíduos, a identidade de gênero das vítimas ainda aparece vinculada ao termo "transexual" acompanhado de acepções masculinas.

No campo da teleficção, a novela da Globo A Força do Querer, escrita por Glória Perez, notabilizou os transgêneros e os dilemas de uma identidade em transformação despertando maior interesse pelo assunto. A partir de Ivana (Carol Duarte), do personagem Nonato (Silvero Pereira), artista transformista, e da escalação do elenco do folhetim, que incluiu a atriz trans Maria Clara Spinelli (a secretária Mira), a dramaturgia, apesar da versão romanceada própria do formato, direcionou os holofotes para essas questões. No entanto, a caricatura e o sarcasmo em torno de personagens trans ou homossexuais permeiam produções humorísticas reforçando estereótipos que reproduzem e/ou alimentam os preconceitos.

Ao longo das décadas, a transexualidade emergiu no cinema. Porém, Saleiro (2013) observa que os enfoques dos filmes eram associados a personagens desequilibradas, perigosas e até mesmo assassinas, como ocorreu nas produções Psico (Alfred Hitchcock, 1960), e Vestida para Matar (Brian de Palma, 1980). A autora interpreta que essa visibilidade negativa amplia a desconfiança em torno 
das pessoas trans, subvertendo a realidade social, pois o segmento, ao contrário de "algoz", é vítima de exclusão; mais vulnerável à discriminação e à violência.

Nos sucessos cinematográficos de crítica, como em Boys Don't Cry (Kimberly Peirce,1999), baseado na história verídica de Brandon Teena, ou na ficção científica Transamerica (Duncan Tucker, 2005), há uma sutil mudança nesse perfil, mas não suficiente para traduzir o drama desses personagens. Em A garota Dinamarquesa (Tom Hopper, 2016), adaptação do livro homônimo de David Ebershoff, conhecemos a história do pintor Einar Wegener, posteriormente Lili, uma mulher transexual na década de 1910, submetida à cirurgia de conversão sexual, que era de alto risco na época. Protagonizado por Eddie Redmayne, o filme contribuiu para o debate traduzindo com significativo grau de representação as dores e os sofrimentos do processo de (re)construção identitária.

Em linhas gerais, as "histórias" do campo da ficção ainda se baseiam no binarismo biológico/natural em matéria de sexo ao invés de discutirem a apropriação ideológica da sociedade na manutenção dos marcadores e enquadramentos sobre a sexualidade. Precisamos, pois, de histórias reais.

Como evidencia Lopes (2004), faz-se urgente o resgate das narrativas de testemunho, das autobiografias, dos diários, não só como alternativas de participação do outro nas pesquisas e nas reportagens. Mas para realizar uma politização da experiência privada dos sujeitos excluídos da sociedade e das formas tradicionais do conhecimento científico. Segundo o autor, as falas e escrituras não são atos narcisistas, mas espaços de contextualização do lugar de fala dos diferentes para torná-lo mais concreto.

Nessa perspectiva, as palavras do outro solicitam a sensibilidade da escuta. Que sejamos, então, capazes de sentir o que dizem as vozes trans.

\section{Quem sou eu? Narrativas e subjetividades sobre "ser menino ou menina"}

Após os sucintos registros do binômio mídia e sexualidade daremos destaque às narrativas trans, buscando respaldo para a inteligibilidade das falas em Goffman (1988) e Bhabha (2005), autores que integram a revisão de literatura do estudo que embasa este texto. 
Os pesquisados ${ }^{12}$ integram um projeto de inclusão social de uma clínica particular de Psicologia do município de Campina Grande, na Paraíba. Cerca de quinze pacientes, homossexuais e transexuais, incluindo nossos interlocutores, participam de terapias transpessoais e grupais. O objetivo do apoio psicológico é facilitar a aceitação e o entendimento das novas subjetividades, uma vez que alguns/algumas não sabem lidar com as desconstruções das identidades anteriores, que marcam um reconhecimento de si no cruzamento com tensões e dilemas do processo.

Nenhum dos/das entrevistados/das permitiu fotos. Contudo, assinaram o termo de consentimento, no qual havia a opção da troca de nomes e a solicitação de imagens como determinam os critérios éticos das pesquisas científicas. De acordo com as condições postas, os diálogos ocorreram em julho de 2017. Em razão dos limites de um artigo selecionamos duas narrativas que notabilizam os estigmas enfrentados pelos/pelas transexuais.

Goffman (1988) elucida que os estigmas se referem ao conjunto de atributos inscritos na identidade de um indivíduo, que, em situação de interação coletiva, podem desacreditá-lo/depreciá-lo, tornando-o "menor" socialmente. Entre as minorias sexuais, o preconceito alimenta as diferenças entre os indivíduos discriminados e os outros grupos, que correspondem aos padrões sociais esperados. Como consequência, uma visão depreciativa de si forja interditos e impede as relações humanas em sua integralidade. Nesse sentido, o medo da rejeição e da violência alcança essas pessoas "surgindo da parte dos excluídos, sentimentos de temor, vergonha, humilhação, impureza e contaminação" (GOFFMAN, 1988, p. 14).

Os indivíduos trans constituem exemplos paradigmáticos dos sofrimentos acionados pelos estigmas. A trajetória de Mariza'3, uma enfermeira loira de 35 anos, trans mulher, confirma essa perspectiva. Demonstrando uma postura de simpatia, ela conversou conosco enquanto esperava uma sessão de terapia individual. Apresentamos aqui uma parte do diálogo acrescida de um resumo da sua história.

Perguntamos seu nome de nascimento, mas não nos contou "nem sob tortura, porque era muito feio" (Dá uma gargalhada). Sabe que foi uma homenagem ao seu avô por ser a primeira neta da família. Em seguida, menciona que se reconhe-

\footnotetext{
12 Soubemos da clínica durante conversas informais no trabalho de campo nas Igrejas Inclusivas. Localizamos dez pacientes e dois psicólogos. Oito pacientes conversaram conosco. Tentamos efetivar ainda uma observação das terapias, mas esse procedimento foi desaconselhado pelos profissionais, porque, no seu entender, iria inibir os depoimentos proferidos nas sessões. Recorremos, então, às entrevistas em profundidade, sem roteiro delimitado, optando por dirigir questões somente em situações específicas ou sugeridas nas falas. O que nos mobilizou foi a sensibilidade da escuta nos cotidianos (ALVES, 2008). Por isso, não determinamos tempo para os registros a fim de compreender os ritmos de raciocínio, as lembranças, as interrupções, hesitações e, sobretudo, as emoções dos falantes.

13 Nome alterado a pedido da entrevistada.
} 
ce no corpo de menina desde a primeira infância. Sempre que sua mãe a vestia para os passeios de domingo, quando tinha cinco anos, chorava muito porque não gostava daquelas roupas: "Eram camisas de linho com mangas compridas e calças compridas, sabe? Arranhava a pele e coçava, além de fazer muito calor: uma aflição!"14 (Mariza, informação verbal).

Descreve brevemente o seu processo de escolarização:

Quando cheguei na escola, que era perto de casa, tinha mais meninas do que meninos. Na alfabetização tinha seis meninos e o resto, menina: umas 10. Eu não brincava com os meninos, só com as meninas. Elas eram boazinhas comigo e deixavam eu brincar com as bonecas delas. Uma vez coloquei uma na minha mochila. [...] Era uma boneca Suzy, porque na época não tinha Barbie [...] Aquela boneca foi meu primeiro objeto de menina (Mariza, informação verbal).

Aos 8 anos começou a usar, escondida, a maquiagem da mãe, principalmente os batons, e conta, sorrindo, que seu maior sonho era usar sutiã:

Um dia meu pai chegou do banco (ele era gerente) e me pegou de sombra verde, batom vermelho e uns brincos de pérola de pressão, porque minha mãe não tinha orelha furada! E ainda com um sutiã cheio de algodão! Aí você imagina o que aconteceu, né? [Ela sorri!] Levei uma surra histórica! (Mariza, informação verbal).

"E as meninas lhe olhavam de modo diferente?" Perguntamos. Mariza responde que não:

Agora sei que não havia preconceito da parte delas. Eram meninas puras, inocentes. Mas os meninos eram maus, davam beliscão em mim e saiam correndo: me xingavam de 'bichona', 'cabelo espetado', 'macarrão veado'. Eu nem sabia o que era bullying e já era vítima na escola! (Mariza, informação verbal).

Ainda recorda:

Aos 18 anos tive a certeza que queria ser enfermeira pra cuidar dos outros, sabe? Gosto muito de idosos! E sabia que era mulher mesmo; nunca fui homem, nem quando meu cabelo era 'Joaozinho'. Minha voz

14 Depoimentos concedidos pela entrevistada Mariza à pesquisadora, em julho de 2017. 
sempre foi assim, fina, sabe? O universo conspirou! (Dá uma gargaIhada!). Mas meu pai, quando bebia, dizia pros amigos que tinha um filho gay, 'biba', debochando de mim, mas depois chorava e dizia que devia ser assim comigo porque 'eu era sozinho, filho único'. Nunca entendeu que eu não era gay. Já morreu, coitado. $\mathrm{O}$ alcoolismo foi o fim dele! (Mariza, informação verbal).

Nesse momento, ela se emociona: Mas eu não queria isso, que ele morresse sem me entender, sem falar comigo. Mas sabe o que ele fez pra se livrar de mim? Me mandou pra casa da minha tia no Rio de Janeiro, sem saber que tava era me fazendo o bem". (Mariza, informação verbal).

Conta sobre sua formação acadêmica:

Fui fazer enfermagem. Dividi apartamento com umas colegas porque minha tia também passou a me discriminar, ter vergonha do meu "rebolado". No prédio eu conheci um médico muito bacana que não me tratava mal por eu ser "afetada", sabe? Ele trabalhava no hospital. Aí eu fui ser instrumentadora dele nas cirurgias, no estágio de final de curso. Ele me disse que tinha um sobrinho igual a mim; que nunca tinha se visto como homem e que tinha feito uma cirurgia para extirpar os genitais. Aí eu pensei: 'foi Deus que botou esse homem no meu caminho, que também me orientou como entrar na justiça pra ter direito ao nome social. Então você já deve adivinhar o resto da história: fiz a cirurgia dois anos depois e no mesmo período implantei silicone no quadril e nas mamas; tudo consegui pelo SUS, e ele me ajudou financeiramente, porque eu nasci linda, mas não rica, né? [Aplaude e dá outra gargalhada!]. Olha como ficou bonito! [Toca nos seios, orgulhosa do resultado! E mostra também o aplique do cabelo para ampliar a extensão dos fios loiros] (Mariza, informação verbal).

Cinco anos depois da cirurgia voltou à Paraíba, após a morte da mãe, para resolver questões jurídicas de inventário e pensão. Diz que a cidade ficou "em choque" (numa expressão sua) com a nova aparência! Herdou a casa da família, porém preferiu vender o imóvel por não gostar da cidade natal. Comprou um apartamento em Campina Grande e trabalha em uma clínica especializada na terceira idade. Em suas palavras:

Gosto muito das velhinhas! Até pinto as unhas delas e isso é uma distração pra mim! Elas nem imaginam o que eu sofri. Acham que minha 
aparência foi sempre 'trabalhada na cor' [diz e sorri...] A terapia tá ajudando a me conhecer melhor, sabe? Apesar do riso frouxo, tenho uma tendência muito grande à depressão, só meu coração sabe... É muita tristeza por causa das hipocrisias, dos julgamentos das pessoas. Para muitas a gente nem existe!" [Os olhos enchem de lágrimas!] (Mariza, informação verbal).

Espontaneamente, Mariza comenta as representações da mídia em relação aos sujeitos trans:

Só notícia de obituário, menina! Que fulano de tal morreu ou apanhou de pedra na rua. Crimes de homofobia, sabe? A travesti fulana de tal foi violentada! E com os trans é ainda pior, menos matéria, nem sabem o que é isso, confundem tudo. Ou quando fazem matéria é pra rir da nossa cara, mostrar caricaturas. Na novela das nove tem um caso (faz referência à trama $A$ força do Querer), mas mesmo assim não dá uma ideia do sofrimento. Dizem que tem também uma série num canal pago ${ }^{15}$... Eu ainda não assisti, então não sei! Triste demais não olharem pra gente! (Mariza, informação verbal).

A identificação é um caminho para a construção da alteridade de gênero. A alteridade, por sua vez, sugere conjunção com uma igualdade política, emancipatória, que inclui não só o sexo, enquanto condição de existência individual na sociedade, mas que ratifica, sobretudo, as heterogeneidades em suas complexidades sócio-históricas e os "discursos do eu" para romper os silenciamentos (BHABHA, 2005).

$\mathrm{Na}$ dimensão social, as diferenças transformam o conceito de igualdade e acenam para a necessidade de uma nova política civilizatória. As tensões do âmbito coletivo se transmutam para a esfera individual, e vice-versa, compondo as vivências complexas das interações cotidianas. Por isso, a alteridade envolve entrelugares, não lugares, entretempos, estranhamentos, intervalos e vidas duplas que colocam em perspectiva as possibilidades de deslocamento da identidade cultural, tal como enfatiza Hall (2004). As diferenças, portanto, impulsionam a construção de alteridades ao mesmo tempo em que implicam sentimentos de desterritorialização na busca de autoconhecimento.

\footnotetext{
15 Referência à série do GNT Liberdade de Gênero, dirigida e produzida pelo cineasta João Jardim, que mostra histórias de pessoas de vários estados brasileiros que não se identificam com o gênero de nascimento. Homenstrans, mulheres-trans, indivíduos não binários abordam as questões da transexualidade narrando os dramas e desafios do convívio em uma sociedade heteronormativa.
} 
Nosso segundo interlocutor é Ricardo ${ }^{16}$, hoje com 35 anos, que, em seus termos, "nasceu menina, mas isso foi uma fatalidade do destino"17 (Ricardo, informação verbal). Seu nome de registro é Jéssica. Nasceu no sertão da Paraíba, no município de Pombal, e, segundo seus termos, "uma terra cheia de preconceitos, onde a mentalidade das pessoas é estreita e mesquinha! Não tenho saudades de lá!"

Resume sua trajetória através da sociabilidade do mundo do trabalho. Narra que saiu do sertão com 20 anos para cursar Farmácia na capital, João Pessoa. Mas como tinha habilidades no ramo da informática, acabou desistindo para trabalhar em empresas de tecnologia:

"Todo trans homem se depara com muito preconceito. Quando fui fazer a entrevista nessa empresa me chamaram pelo nome 'oficial'. Não respondi. Mas como eu tava com trajes masculinos pensaram que a candidata à vaga tinha faltado, e me chamaram. Expliquei que havia nascido mulher, mas que sempre me senti como homem. Contei dos hormônios que comecei a tomar aos 18 anos, da mudança das roupas. Sempre gostei de falar! E aí o chefe perguntou: 'E você usa qual banheiro? Quer dizer, o vaso sanitário tem que ser de homem ou de mulher?' (Ricardo, informação verbal).

Ricardo sorri ao lembrar o episódio. Contou ainda que não tem nome social, mas deu entrada na justiça. Acredita que vai evitar constrangimentos, porque, no final da entrevista de emprego, o homem ainda disse:

Olha, se der certo, eu contrato você, sim, porque sou uma pessoa aberta, sem preconceito com homossexual!'. Aí eu falei pra ele que não era gay. Que era trans. Aí ele quis saber: 'Então você não tem vagina?' Eu falei: “Mas isso não faz diferença, porque me sinto homem (Ricardo, informação verbal).

Continuando o interrogatório desconfortável, o superior insistiu:

'E não usa sutiã, não'? Aí eu expliquei que o uso da faixa vai apertando os músculos, atrofiando os órgãos femininos, então o tórax fica mais liso. Os pelos ajudam a aparência masculina. A voz vai mudando também. 'E você namora?' Aí eu fui ficando impaciente e disse que minha sexualidade não tinha a ver com a transição de gênero. E que

16 Nome fictício sugerido pelo entrevistado.

17 Depoimento concedido pelo entrevistado Ricardo à pesquisadora, no dia em julho de 2017. 
era uma questão muito pessoal, não de trabalho! Aí ele se aborreceu e me mandou sair... Mas avisou que se eu tivesse sido aprovado na entrevista, alguém da empresa ligaria. 15 dias depois ligaram e fui trabalhar com eles (Ricardo, informação verbal)

Hoje, Ricardo declara que a convivência com a chefia e os colegas é tranquila e que sua vida é muito pacata: o máximo que acontece em termos de lazer é tomar umas cervejas no final de semana. Não é mais católico, porque, sob influência da família, foi conhecer uma igreja evangélica. Mas quando soube da sua história de vida, o pastor the pediu para não frequentar os cultos, "porque chamava a atenção das pessoas": -"Eu fiquei decepcionado! Como é que uma pessoa que se diz caridosa trata as outras desse jeito? Então desisti de frequentar igreja" (Ricardo, informação verbal).

No que tange à mídia, Ricardo lembra que vê alguns fatos isolados sobre pessoas trans nos telejornais:

\begin{abstract}
Sai muita notícia de violência. Mas a mídia dá mais espaço para artistas, como tá acontecendo com a Pablo Vittar ${ }^{18}$. Acho que na música tem mais notícias, sim! A novela da Globo falou disso, mas achei muito fantasiosa, principalmente a gravidez do Ivan... Devia sair mais nos jornais, na TV, ter mais informação sobre a gente! [...] Pois a gente é normal! Mas o que é ser 'normal'? Viver num corpo que a gente rejeita? Viver fingindo? (Ricardo, informação verbal)
\end{abstract}

"Mas você está feliz"? Questionamos, e ele também nos interpela: "Se você não soubesse que um dia eu fui menina, pensaria que sou um homem? Mesmo com essa voz estranha?", Insiste. "Claro que sim. Você tem aparência masculina!", respondemos. "Pois é, 'aparência' (enfatiza a palavra!). [...] Mas as aparências sempre enganam! Tem muito preconceito na mídia e isso chega nas pessoas. Seria mais fácil se eu fosse gay!", finaliza. Ele se afasta, alegando que vai buscar um café, mas, na verdade, segue para o estacionamento como se pretendesse, literalmente, deixar para trás um passado de dor e rejeição.

Não foram identificadas formas de manipulação do estigma social que, conforme Goffman (1988), revelam duas estratégias: o "encobrimento" (esconder o estigma) e o "acobertamento" (tentativa de diminuir a tensão que o estigma traz às interações, por parte do estigmatizado. Disfarçar, de algum modo, o

18 Phabullo Rodrigues da Silva, nascido em São Luís, Maranhão, adotou o nome artístico Pabllo Vittar. É cantor, compositor e drag queen. 
que é visto como defeito aos olhos dos outros). Ao contrário, Mariza e Ricardo afirmam sua transexualidade e se mostram satisfeitos com o estágio atual vivido, embora admitam o sofrimento que envolve a autoafirmação por gerar "oposição da ordem social", nas palavras de Bourdieu (2009).

Saleiro (2013) aponta que os tensionamentos da relação incomum entre sexo (biológico) e gênero (social) caracteriza o fenômeno que nas ciências psico-médicas é conhecido como "disforia de gênero" ou "perturbação da identidade de gênero". Fora dos limites e equívocos das classificações, em termos socioantropológicos, a palavra trans equivale a modos diversos de experienciar a sexualidade para além das definições convencionais. As identidades de gênero e as diferenças sexuais possuem definições provisórias abertas à negociação social. Portanto, só podem ser pensadas cultural e historicamente.

Entretanto, como reitera Ceccarelli (2010), o imaginário social alimenta uma correspondência "natural" entre sentir-se homem (sexo) e ser masculino (gênero), e o sentir-se mulher (sexo) e ser feminina (gênero), em uma pseudo impressão de que haveria relação direta entre corpo anatômico e identidade de gênero. A identidade de gênero trans, por se reportar à ordem das pulsões subjetivas, impulsiona uma adaptação de corpos ao sentimento sexual que lhes é predominante.

Assim, o vocábulo trans tanto se refere às pessoas que realizam intervenções médicas, incluindo as cirúrgicas, para se tornarem "biologicamente" do sexo "oposto" com o qual se identificam, como se refere àqueles e àquelas que não tencionam realizar intervenções cirúrgicas ou, necessariamente, passar por uma transição física. Saleiro (2013) acredita que a distinção entre transexual e transgênero, baseada na extensão das intervenções corporais ou, mais precisamente, da cirurgia genital, parece constituir mais uma visão social "simplista" acerca de um tema cuja complexidade requer informações contextualizadas.

Nessa linha argumentativa, Santos (2003) considera que existe em cada um de nós uma cegueira epistemológica, oriunda da parcialidade de nossa visão, desenvolvida no seio de uma cultura parcial e redutora. Para ele, a superação do reducionismo começa pelo entendimento da cultura no plural. Por esse viés, as vivências da transexualidade são atos culturais singulares, que exigem debates em torno das minorias discriminadas e de suas capacidades de resiliência. Ser menino ou menina diz respeito ao sexo de atribuição, e não à biologia genital. Logo, a diversidade de gênero deve ser pensada em uma democracia plural que transforme "as identidades de si deterioradas" (GOFFMAN, 1988). 


\section{Palavra (sem) final}

Em síntese, a transexualidade revela o caráter incerto dos sentidos de masculinidade ou feminilidade nas escolhas de si. É uma possibilidade de transformação, uma afirmação de liberdade para indivíduos aprisionados em corpos errados, que podem forjar uma versão exterior dos seres que suas almas já conhecem. Por isso, as narrativas expostas revelam singularidades conflituosas. A verossimilhança das falas se conecta aos desafios cotidianos de quem contradiz a heteronormatividade de gênero em um processo de transição que soa "previsível" para quem não o viveu, mas muito doloroso para quem o experimenta.

Em uma época em que alguns falam em construir muros de segregação humana, pensemos em pontes que facultem às pessoas trans o direito de ir e vir com suas diferenças, exercendo igualmente suas cidadanias em um mundo menos hostil, mais empático e respeitoso. Isso se faz urgente em uma contemporaneidade marcada por intolerâncias que aniquilam os diferentes.

As histórias reais de Mariza e Ricardo nos impactam, porque mostram que viver juntos não é uma questão de anatomia. Não compõem enredos de ficção; são representações de muitas outras histórias que não conhecemos. Inspiram uma agenda midiática que trate dos hibridismos das sexualidades para além da violência que os afeta.

Que possamos, então, falar sobre pessoas. E que eles e elas se pronunciem para corresponder às demandas do tema; que se vejam e sejam vistos/as. E que as pesquisas, para além dos enquadramentos das áreas acadêmicas, possam se interessar, com humanidade, pelas falas da diversidade sexual; analisar quem são seus sujeitos, a partir dos ditos e interditos, como protagonistas de suas escolhas e destinos, como artífices de suas alteridades.

As interlocuções compartilhadas aqui dão um passo nessa direção expondo novas formas de ser que interrogam as assimetrias e hierarquias culturais, transmitindo a afetividade e os embates cotidianos, as visões de mundo e as esperanças das pessoas. Denotam sensibilidades, lutas e (re)construções identitárias em busca de validação à revelia de uma sociedade preconceituosa que as relega ao silenciamento e à invisibilidade. 


\section{Referências}

ALVES, Nilda. Sobre movimentos das pesquisas nos/dos/com os cotidianos. In: OLIVEIRA, Inês Barbosa de; ALVES, Nilda (org.). Pesquisa nos/dos/com os cotidianos das escolas: sobre redes de saberes. Rio de Janeiro: DP\&A, 2008.

BENTO, Berenice Alves de Melo. O que é transexualidade. São Paulo: Brasiliense, 2008. BHABHA, Homi K. O local da cultura. Belo Horizonte: Ed. UFMG, 2005.

BORDIEU, Pierre. A dominação masculina. Rio de Janeiro: Bertrand Brasil, 2009.

CECCARELLI, Paulo Roberto. Psicanálise, sexo e gênero: algumas reflexões. In: RIAL, Carmen; PEDRO, Joana Maria; FÁVERO, Silvia Maria (orgs). Diversidades: dimensões de gênero e sexualidade. Santa Catarina: Editora Mulheres, 2010.

GOFFMAN, Erving. Estigma: notas sobre a manipulação da identidade deteriorada. Rio de Janeiro: Guanabara, 1988.

HALL, Stuart. A identidade cultural na pós-modernidade. Rio de Janeiro: DP\&A, 2004.

LEAL, Bruno Souza; CARVALHO, Carlos Alberto de. Sobre jornalismo e homofobia ou: pensa que é fácil falar? E-compós, Brasília, v. 12, n. 2, maio/ago, 2009. https://doi. org/10.30962/ec.v12i2.214

LOPES, Denílson. Desafios dos estudos gays, lésbicos e transgêneros. Revista Comunicação, Mídia e Consumo, São Paulo, v. 1, n. 1, p. 63-73, 2004.

LOURO, Guacira Lopes. Um corpo estranho - ensaios sobre sexualidade e Teoria queer, Belo Horizonte: Autêntica, 2013.

MAFFESOLI, Michel. Elogio da razão sensível. Rio de Janeiro/Petrópolis: Vozes, 2005. MARTÍN-BARBERO, Jesús. Uma aventura epistemológica. [Entrevista concedida] à Maria Immacolata Vassalo de Lopes. Matrizes, v. 2, n. 2, 2009. https://doi.org/10.11606/ issn.1982-8160.v2i2p143-162

MEDINA, Cremilda. A arte de tecer o presente: narrativa e cotidiano. São Paulo: Summus, 2003.

SALEIRO, Sandra Palma. Trans Géneros: Uma abordagem sociológica da diversidade de género. Tese. Doutorado em Sociologia. ISCTE - Instituto Universitário de Lisboa, Portugal, 2013.

SANTOS, Boaventura Sousa. Por uma concepção multicultural de direitos humanos. In: SANTOS, Boaventura Sousa (org.). Reconhecer para libertar: os caminhos do cosmopolitismo multicultural. Rio de Janeiro: Civilização Brasileira, 2003. 
SILVA, Tadeu Tomaz da. A produção social da identidade e da diferença. In: SILVA, Tadeu Tomaz da (org.). Identidade e diferença: a perspectiva dos Estudos Culturais. Petrópolis, RJ: Vozes, 2008.

\section{Dados da autora:}

Robéria Nádia Araújo Nascimento - rnadia@terra.com.br

Professora do Programa de Pós-Graduação em Formação de Professores da Universidade Estadual da Paraíba - UEPB. Doutora em Educação pela Universidade Federal da Paraíba - UFPB.

Endereço da autora: Universidade Estadual da Paraíba, Programa de PósGraduação em Formação de Professores. Rua Domitila Cabral de Castro, s/n, $3^{\circ}$ andar, Sala 327, Bairro Universitário, 58.429-570 - Campina Grande (PB) - Brasil 